Kamil OSTAPOWICZ ${ }^{1}$

Opiekun naukowy: Piotr DANIELCZYK ${ }^{2}$

DOI: https://doi.org/10.53052/9788366249837.19

\title{
METODA BEZSIATKOWA A METODA ELEMENTÓW SKOŃCZONYCH - STUDIUM PRZYPADKU
}

\begin{abstract}
Streszczenie: W artykule przeprowadzono analizę wytrzymałości konstrukcji haka holowniczego, stosownie do zapisów dyrektywy 94/20/WE. Obliczenia wykonano dwiema metodami: metodą elementów skończonych i metodą bezsiatkową. Porównano uzyskane wyniki. Dokonano oceny obu metod pod kątem czasu niezbędnego do przygotowania modelu obliczeniowego, jak i efektywności numerycznej.

Słowa kluczowe: metoda bezsiatkowa, metoda elementów skończonych, analiza wytrzymałościowa, hak holowniczy
\end{abstract}

\section{MESHLESS METHOD VERSUS THE FINITE ELEMENT METHOD - A CASE STUDY}

Summary: The article presents strength analysis of the towing hook in accordance with the provisions of Directive 94/20/EC. Calculations have been made using two methods: the finite element method and the meshless method. The obtained results have been compared. Both methods have been assessed in terms of the time necessary to prepare the computational model and numerical efficiency.

Keywords: meshless method, finite elements method, strength analysis, towbar

\section{Wprowadzenie}

Metoda elementów skończonych (ang. Finite elements method), oraz metoda bezsiatkowa (ang. Meshless method) są metodami wspierających pracę współczesnego inżyniera. Ta pierwsza, od wielu lat jest uznanym narzędziem analiz

1 Akademia Techniczno-Humanistyczna w Bielsku-Białej, Wydział Budowy Maszyn i Informatyki, Komputerowo wspomagane konstruowanie i wytwarzanie (CAD/CAM), e-mail: ostapowiczkam@gmail.com

2 dr inż., Akademia Techniczno-Humanistyczna w Bielsku-Białej, Wydział Budowy Maszyn i Informatyki, pdanielczyk@ath.bielsko.pl 
obliczeniowych. Zadania rozwiązywane metodą elementów skończonych obejmują wiele dziedzin techniki i nauki, a rezultaty uzyskiwane tą metoda są uznawane za wiarygodne. Przygotowanie analizy metodą elementów skończonych wymaga podjęcia szeregu czynności (rys.1), wpływających na efektywność całego procesu obliczeniowego [1]. Dwa etapy, które wymagają wiedzy i doświadczenia, to przygotowanie modelu geometrycznego oraz jego dyskretyzacja. Poprawne przeprowadzenie tych dwóch etapów powinno prowadzić do modelu, który jest zgodny $\mathrm{z}$ rzeczywistym problemem i daje wystarczająco dokładne wyniki w akceptowalnym czasie. Taki model nazywa się racjonalnym [2].

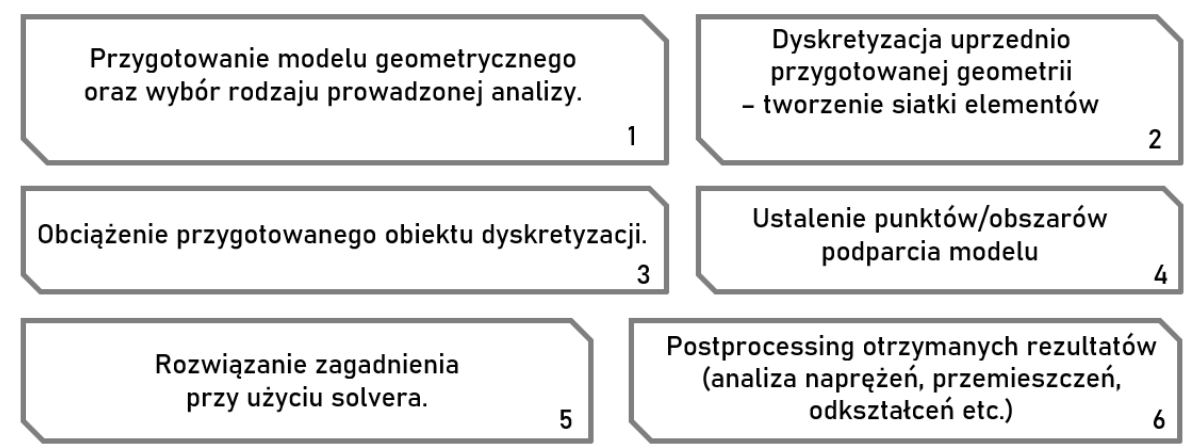

Rysunek 1. Etapy modelowania w metodzie elementów skończonych

Drugą grupą metod obliczeniowych, która zdobywa coraz większe uznanie wśród inżynierów-obliczeniowców są metody bezsiatkowe. Z uwagi na swoją efektywność numeryczną, stają się coraz częściej narzędziem analiz obliczeniowych wykonywanych w praktyce przemysłowej. Inżynierowie wykorzystujący tą metodę zwracają uwagę na łatwość przygotowania modelu obliczeniowego. Szacuje się, że zastosowanie metod bezsiatkowych pozwala na redukcję czasu potrzebnego na analizę nawet o kilkadziesiąt procent, w stosunku do metody elementów skończonych (rys.2) [3].

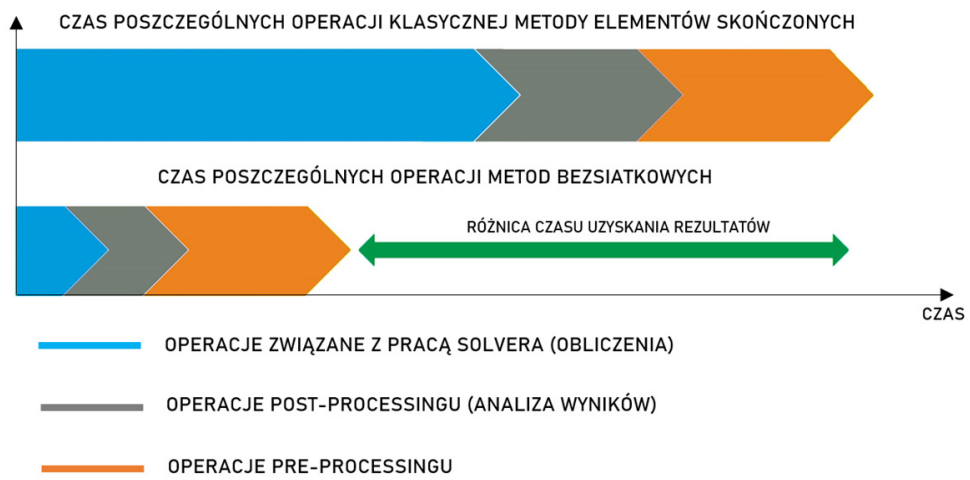

Rysunek 2. Porównanie czasu potrzebnego na uzyskanie rezultatów w klasycznej metodzie MES oraz metodach bezsiatkowych 
Wstępne analizy [4], przeprowadzone dla zadań testowych, takich jak wyznaczanie nośności połączenia śrubowego, analiza modalna belki pryzmatycznej oraz zagadnienie przewodzenia ciepła w płycie wykazały, że zastosowanie do tych analiz metody bezsiatkowej (pakiet Simsolid firmy Altair), w porównaniu z rozwiązaniami analitycznymi oraz rozwiązaniami uzyskanymi metodą elementów skończonych, (pakiet NX firmy Siemens) daje zbliżone wyniki. Z inżynierskiego punktu widzenia różnice wyników pomiędzy metodami (ok. 10\%) są akceptowalne. Trzeba odnotować, że czas przygotowania modelu obliczeniowego oraz czas samych analiz jest znacząco krótszy.

W niniejszej pracy zostanie przedstawione zadanie analizy wytrzymałościowej zespołu haka holowniczego. Wyniki uzyskane $\mathrm{z}$ analizy metodą elementów skończonych oraz wyniki dla metody bezsiatkowej zostaną porównane biorąc pod uwagę dwa aspekty: efektywność numeryczną oraz wysiłek włożony w przygotowanie modelu obliczeniowego, a także, co oczywiste, jakość uzyskiwanych rezultatów.

\section{Obiekt analizy. Wymagania techniczne}

Obiektem analiz przedstawionych w artykule jest rozwiązanie konstrukcyjne haka holowniczego, którego budowę pokazano na rysunku 3. Do belki głównej (2) przyspawane są wsporniki $(3,4)$, a do nich, za pomocą śrub zamocowany jest hak (1). Ramiona mocujące $(5,6)$, przykręcone do belki głównej służą do mocowania zespołu do karoserii pojazdu.

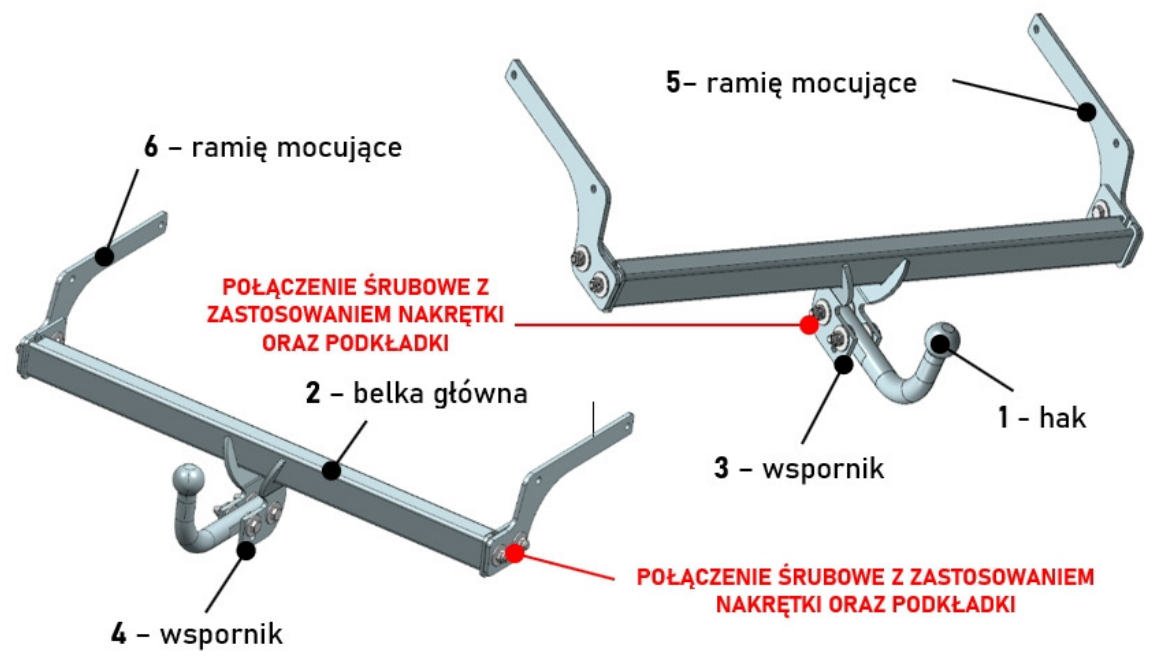

Rysunek 3. Hak holowniczy

Konstrukcja haka holowniczego musi spełniać m.in. wytyczne zawarte w załączniku nr VI pt. Badanie mechanicznych urządzeń sprzęgajacych, dyrektywy 94/20/WE [5]. Określono tam m.in plan badań statycznych, których spełnienie jest wymagane przed 
wprowadzeniem urządzenia do użytku publicznego. Do testów przyjmuje się obciążenie opisane poniższą zależnością:

$$
S=120 \cdot \frac{D}{g}=120 \cdot \frac{20}{9,81} \approx 244 \mathrm{~kg}
$$

gdzie D oznacza teoretyczną tzw. siłę odniesienia, określoną we wspomnianym załączniku. Dla przyczep ze standardowym zaczepem kulowym wartość $D$ wynosi $20 \mathrm{kN}$. Zgodnie zapisami dyrektywy testy należy przeprowadzić dla dwóch kierunków działania siły, tak jak pokazano to na rysunku 4.

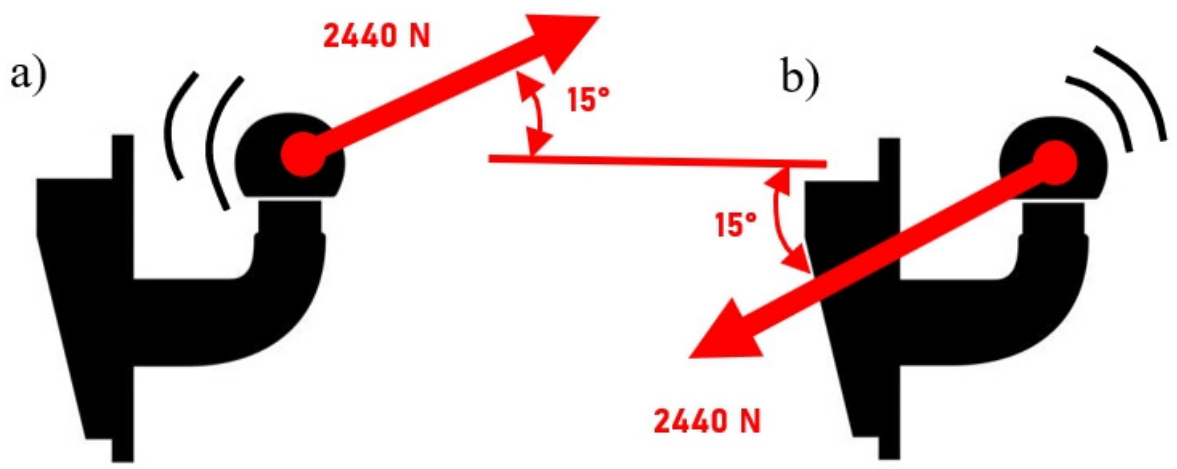

Rysunek 4. Warianty obciążeniowe haka holowniczego

\section{Modele obliczeniowe zespołu haka holowniczego}

Do analiz metodą elementów skończonych w pakiecie NX firmy Siemens opracowano dyskretny model obliczeniowy bazujący na modelu geometrycznym haka. Do dyskretyzacji wykorzystano dziesięciowęzłowe elementy bryłowe typu TETRA10 o wymiarze elementu określonym na $5 \mathrm{~mm}$ (rys.5). Ponadto, na styku części zespołu haka do modelu wstawiono elementy kontaktowe, łączące poszczególne powierzchnie modelu.

W kolejnym kroku określono warunki brzegowe analizy (podparcia i siły). Model został utwierdzony w otworach mocujących zderzak do pojazdu. Siłę obciążająca hak (por.rys.4) rozłożono na dwie składowe i przyłożono do główki haka, tak jak pokazano na rysunku 6. 


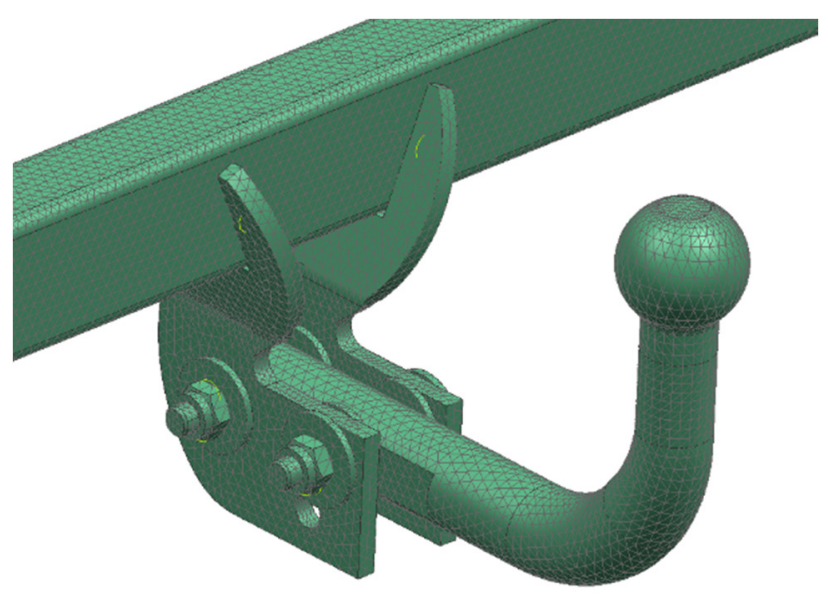

Rysunek 5. Model dyskretny haka holowniczego
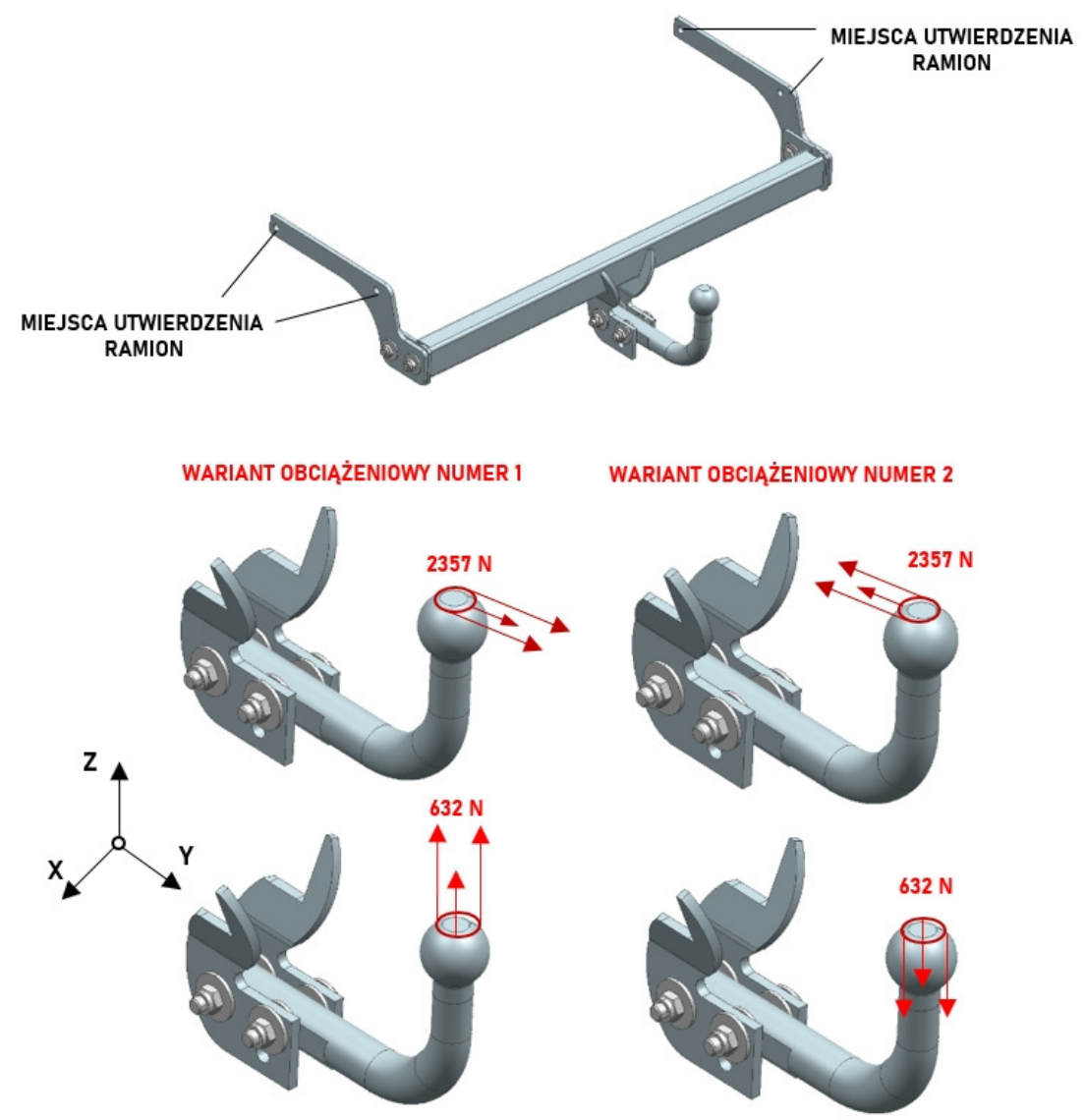

Rysunek 6. Podparcia i obciażenia modelu haka 
Przygotowanie modelu obliczeniowego do analizy metodą bezsiatkową w pakiecie Simsolid firmy Altair jest o wiele prostsze i mniej czasochłonne. W praktyce rola użytkownika ogranicza się określenia warunków brzegowych analizy. Nie zachodzi potrzeba dyskretyzacji obszaru obliczeniowego elementami skończonym, w tym tak czasochłonnej operacji jak wskazanie par elementów kontaktowych w modelu. Wszystkie połączenia są wykrywane i tworzone w sposób automatyczny. W drzewie modelu (rys.7) właściwie mamy zapisane tylko warunki brzegowe analizy.

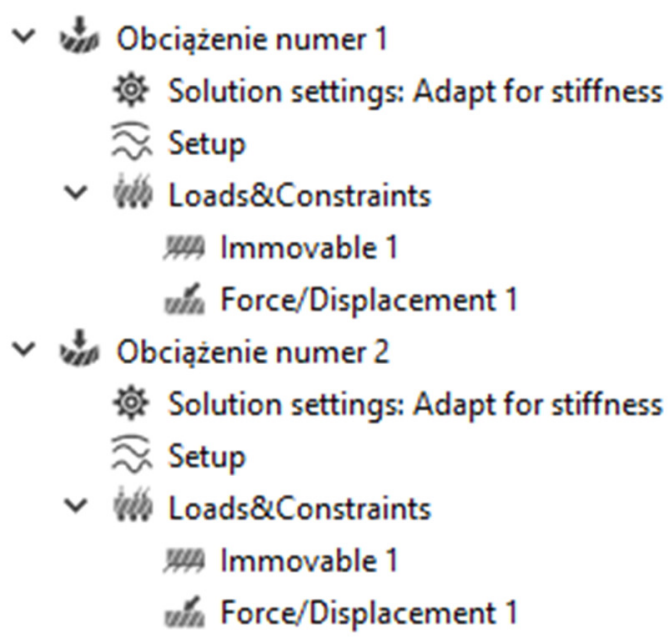

\section{Rysunek 7. Drzewo modelu pakietu Simsolid}

Dla obu wariantów obciążeń rozwiązano zadanie analizy statycznej metoda elementów skończonych oraz metodą bezsiatkową. W wyniku przeprowadzonych obliczeń uzyskano obraz odkształceń oraz rozkłady naprężeń zredukowanych. Ponadto poddano ocenie i porównano czasy przygotowania modelu obliczeniowego jak i czas samego rozwiązania zadania dla obu wykorzystanych metod.

\section{Wyniki obliczeń}

Na rysunku 8 zaprezentowano odkształcenia konstrukcji haka wskutek działania sił zgodnych z pierwszym wariantem obciążenia (por. rys 4a) a na rysunku 9 odkształcenia odpowiadające wariantowi drugiemu (por. rys 4b). Jak można zauważyć wartości maksymalnych odkształceń główki haka, uzyskane obiema metodami obliczeniowymi, dla obu wariantów obliczeń są zbliżone. Różnice wynoszą około $1 \%$. 


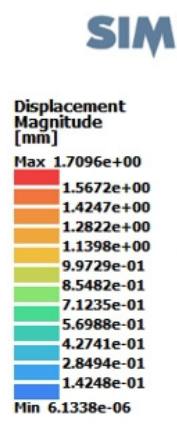

SIMSOLID

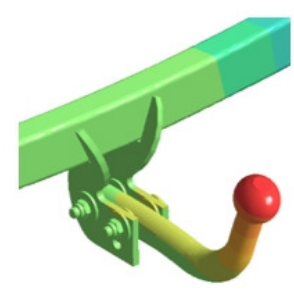

a)

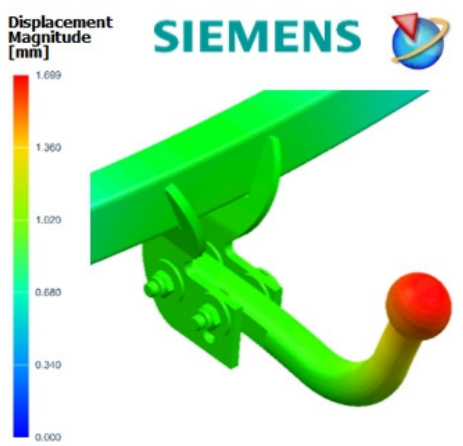

b)

Rysunek 8. Odksztatcenia haka dla pierwszego wariantu obcią̇enia a) uzyskane metoda bezsiatkową b) z analizy metoda elementów skończonych
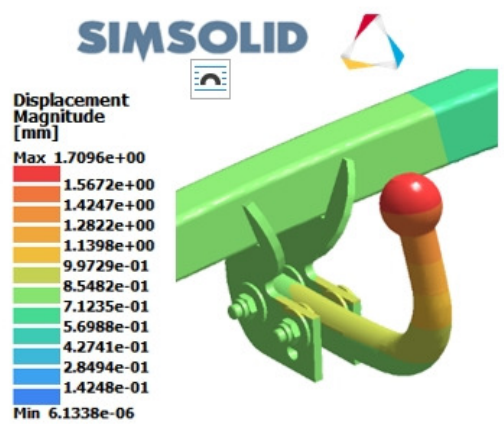

a)

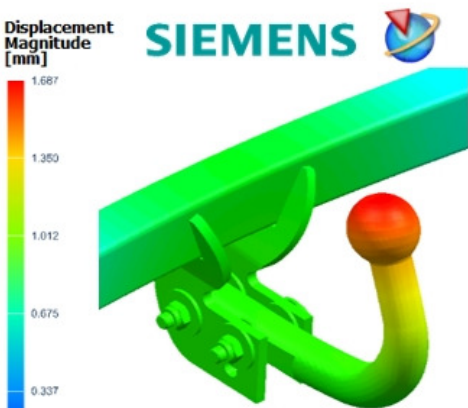

b)

Rysunek 9. Odksztatcenia haka dla drugiego wariantu obciążenia a) uzyskane metoda bezsiatkowa b) z analizy metoda elementów skończonych

$\mathrm{Na}$ kolejnych rysunkach (rys.10 i rys.11) przedstawiono rozkład naprężeń zredukowanych w konstrukcji według hipotezy von Misesa dla pierwszego wariantu obciążenia. Jak można zauważyć, rozkłady te, jak i maksymalne wartości naprężeń są zbliżone (110 MPa w metodzie elementów skończonych, $113 \mathrm{MPa}$ w metodzie bezsiatkowej). Miejsca wystąpienia maksymalnych naprężeń jednak są różne. Analiza metodą elementów skończonych wykazała spiętrzenie naprężeń w okolicach otworu mocującego, natomiast $\mathrm{w}$ metodzie bezsiatkowej jest to miejsce zagięcia haka. W związku z tym, do porównania wyników uzyskanych obiema metodami wzięto pod uwagę ten sam punkt, wyznaczający największe wartości naprężeń w zagięciu haka. Analizując uzyskane rezultaty (rys.12) można stwierdzić, że wyniki uzyskane metodą bezsiatkowa różnią się od wyników z metody elementów skończonych o 9.2\% i są akceptowane dla praktyki inżynierskiej. 


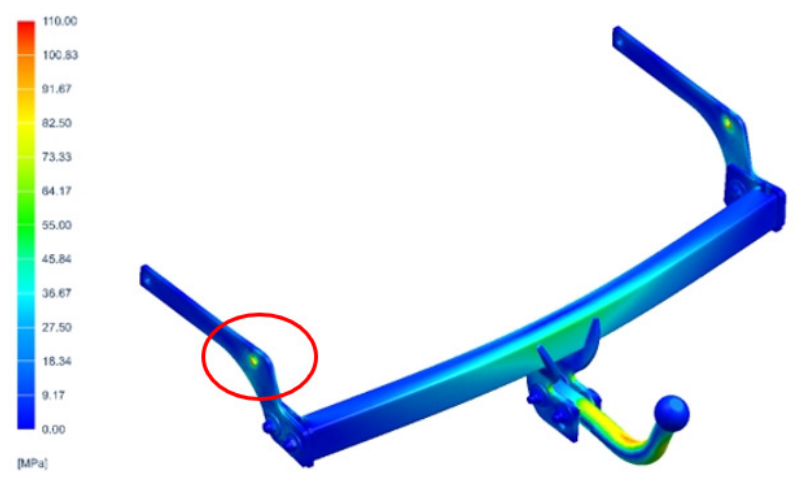

Rysunek 10. Naprężenia w zespole haka dla pierwszego wariantu obciążenia (metoda elementów skończonych)

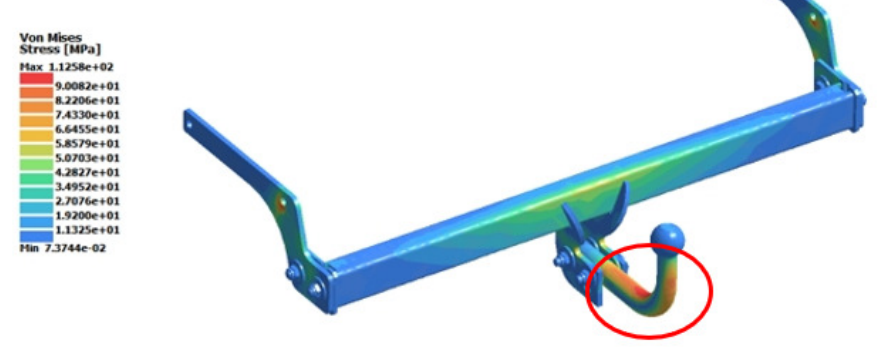

Rysunek 11. Naprężenia w zespole haka dla pierwszego wariantu obciążenia (metoda bezsiatkowa)

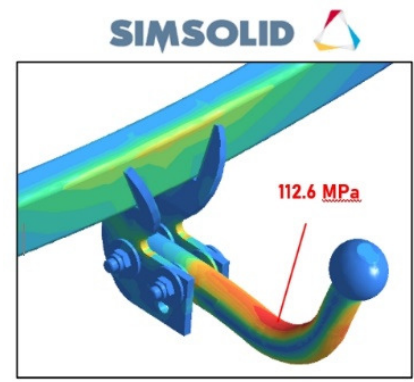

a)

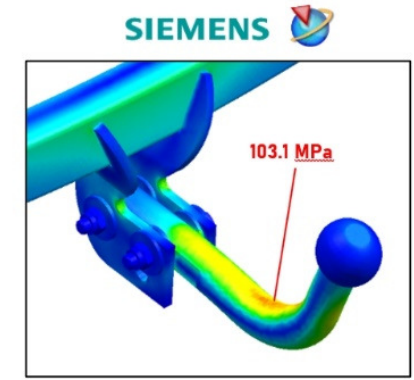

b)

Rysunek 12. Naprężenia w zagięciu haka dla pierwszego wariantu obciażenia a) uzyskane metoda bezsiatkowa b) z analizy metodą elementów skończonych

Wyniki dla drugiego wariantu obliczeniowego prowadzą do podobnych wniosków. Analiza metodą elementów skończonych także wykazała spiętrzenie naprężeń w okolicach otworu mocującego, natomiast w metodzie bezsiatkowej jest to miejsce zagięcia haka (rys.13, rys.14). Podobnie jak poprzednio, do porównania wyników uzyskanych obiema metodami wzięto pod uwagę ten sam punkt, wyznaczający 
największe wartości naprężeń w zagięciu haka. W tym przypadku (rys.15) różnice wynoszą $11.2 \%$.
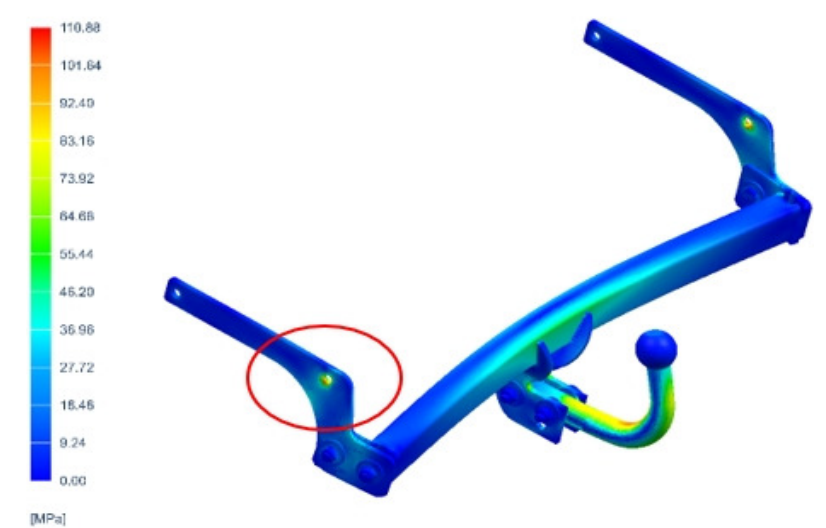

Rysunek 13. Naprężenia w zespole haka dla drugiego wariantu obcią̇enia (metoda elementów skończonych)

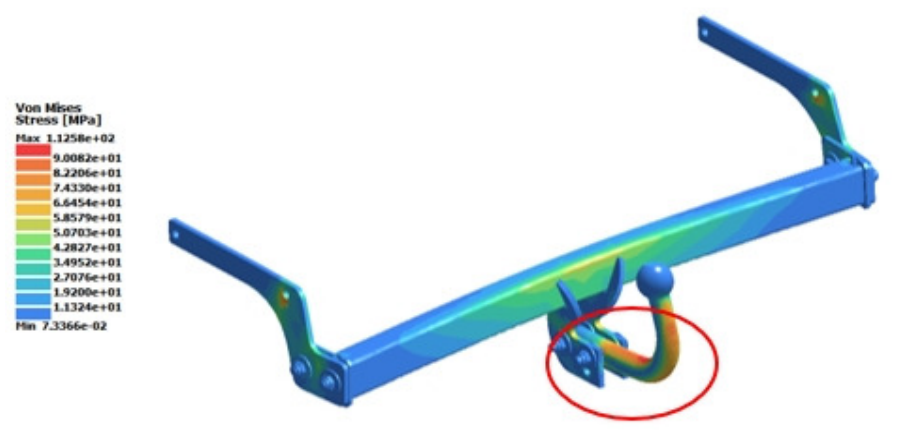

Rysunek 14. Naprężenia $w$ zespole haka dla drugiego wariantu obciązenia (metoda bezsiatkowa)

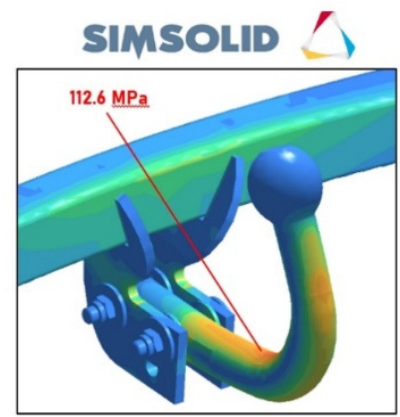

a)

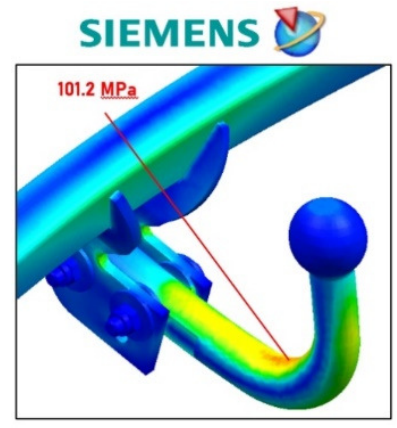

b)

Rysunek 15. Naprężenia $w$ zagięciu haka dla drugiego wariantu obciążenia a) uzyskane metodą bezsiatkowa b) z analizy metoda elementów skończonych 
Dla analiz metodą elementów skończonych i metodą bezsiatkową oszacowano czas przygotowania modelu obliczeniowego oraz zmierzono czas rozwiązywania zadania. Wyniki tych pomiarów przedstawiono w tabeli 1. Jak można zauważyć, różnice w czasie przygotowania analizy jak i czasie obliczeń wypadają zdecydowanie na korzyść metod bezsiatkowych.

Tabela 1 Czasy wykonywania operacji „pre-processingu” oraz obliczeń

\begin{tabular}{|c|c|c|c|}
\hline & MES & $\begin{array}{c}\text { METODA } \\
\text { BEZSIATKOWA }\end{array}$ & RÓŻNICA CZASÓW \\
\hline $\begin{array}{c}\text { CZAS PRZYGOTOWANIA } \\
\text { MODELU OBLICZENIOWEGO }\end{array}$ & $4800 \mathrm{sek}$ & $30 \mathrm{sek}$. & $\begin{array}{c}99.4 \% \\
\text { (względem MES) }\end{array}$ \\
\hline $\begin{array}{c}\text { CZAS PROWADZENIA } \\
\text { OBLICZEŃ }\end{array}$ & $600 \mathrm{sek}$. & $30 \mathrm{sek}$. & $\begin{array}{c}95 \% \\
\text { (względem MES) }\end{array}$ \\
\hline
\end{tabular}

\section{Wnioski i spostrzeżenia}

Wykorzystanie metod bezsiatkowych do analiz wytrzymałości części maszyn i urządzeń daje wymierne korzyści. W stosunku do metody elementów skończonych skraca się znacząco czas przygotowania modelu obliczeniowego jak i czas obliczeń. Korzyści te sięgają, w zależności od typu analizy i stopnia złożoności modelu obliczeniowego od kilkudziesięciu do nawet 99.4\%. Przy czym wyniki uzyskane obiema metodami są zbliżone, a różnice akceptowalne dla praktyki inżynierskiej. $\mathrm{Z}$ tego powodu metody bezsiatkowe są coraz częściej wykorzystywane do wstępnej analizy złożonych obiektów konstrukcyjnych.

\section{LITERATURA}

1. WASSERMAN S.:Structural Software Claims Better Accuracy without Finite Elements, https://www.engineering.com/story/structural-software-claims-betteraccuracy-without-finite-elements.

2. STADNICKI J.: Racjonalność modeli MES części maszyn, Mechanik, 7(2011), 851-860.

3. Film demonstracyjny dla technologii SIMSOLID, 2018, https://www.youtube.com/watch? $v=0 f X 7 o R o N B e U$.

4. OSTAPOWICZ K.: Metody bezsiatkowe a metoda elementów skończonych porównanie wyników analiz dla wybranych konstrukcji, Praca magisterska, Akademia Techniczno-Humanistyczna w Bielsku Białej, 2021.

5. Dyrektywa 94/20/WE z dnia 30.05.1994 r. odnosząca się do mechanicznych urządzeń sprzęgających pojazdów silnikowych i ich przyczep oraz systemów ich mocowania do tych pojazdów - Dz. U. L 195. Z 29.07.1994 r. 